\title{
BILINGUAL SEMANTIC REPRESENTATION AND LEXICAL ACCESS
}

\author{
JUDIT NAVRACSICS
}

\begin{abstract}
This study presents evidence concerning semantic representation in bilingual memory. A vast majority of the early research on this topic proposed that fluent bilinguals access semantic representations that are shared across their two languages. More recent research proves that the question is not as simple as that. Bilinguals can sometimes use shared semantic representations across their two languages, but the conditions under which they can do so are constrained by the nature of the material, by the form of the task, by the level of proficiency in the second language, and by the lexical-level connections between the two languages. The present study provides an analysis of some psycholinguistic tests carried out among bilingual and bicultural people within a new framework proposing that there are asymmetries in the strength of the connections between lexical representations in different languages and between lexical representations and concepts. I will examine bilingual and bicultural semantic representations and their linguistic realisations, and the switching attitudes of bilinguals through the analysis of three tests conducted among bilingual and bicultural subjects.
\end{abstract}

\section{Introduction}

The mental lexicon is a kind of internal dictionary which contains not only the 'entries' for each word a speaker knows but also all the linguistic information about the word: its semantic content, syntactic properties, phonological shape, etc. Semantic memory, which is reflected in the lexicon, is not strictly linguistic since it contains the mental representation of the individual's knowledge of the world. This knowledge is represented in concepts and relations between these concepts (Appel-Muysken 1987). Studies of mental structure have never been easy to conduct and descriptions of cognitive and linguistic development are always fraught with inference and uncertainty. These difficulties are compounded when two languages occupy the linguistic domain of a person's mind (Bialystok 1998).

When studying the semantic representation of bilinguals, the structure of the bilingual mental lexicon and the connections of language, thought and culture must also be taken into consideration. 
Languages reflect the culture, beliefs, values and identity of people who speak them (Baker-Jones 1998). Culture is something that everybody has. It is not what is found in theatres, museums, universities, etc. The term refers to some property of a community which the members share and which might distinguish it from other communities (Hudson 1986). The connections between language, thought and culture have always been in the focus of attention.

The well-known Sapir-Whorfian hypothesis claims that language has a determining role over thought. Sapir spoke about language as a "tyrant" which defines experience, imposing upon us particular ideas about the world (cf. Steinberg 1993). Humboldt in 1836 declared that a language by its very nature represented the spirit and national character of a people. With reference to this statement, a German teacher was dismissed in the US after World War I, for fear of his influence upon the students' developing character. According to Whorf, speakers of different languages are led by the same physical evidence to the same picture of the universe only to the extent that "their linguistic backgrounds are similar or can in some way be calibrated".

From a psycholinguistic point of view, there are at least three considerable arguments against this presumption.

(i) If one holds that language is the basis for thought, one would have to argue that deaf children do not think. However, cognition can develop to a certain extent even in the absence of knowledge of any language. The reverse does not hold true.

(ii) Language can begin to be learned only when thought is sufficiently developed through the child's experience of objects, events and situations in the world (Steinberg 1993).

(iii) If the Sapir-Whorfian view were possible to be held, the multilingual would have as many different conceptual-perceptual systems of the physical world as many languages he or she has. If the language system formed thought, and if different languages formed different systems, then bi- or multilinguals would form more than one system of thought. If multilingual persons had many different thought processes, such persons would not have coherent intelligence or personalities (Steinberg 1992). Different ideas would be involved with the different languages. Then bilinguals would have difficulty in using the knowledge gained through one language when operating in the other language.

\subsection{Mental representation}

Our mental system provides us with an internal representation of the world, a microcosm, but that is certainly not a miniature world. It is what projects 
the projected world. In addition, it builds further structure by its own internal processing: thinking, figuring things out, deducing things, imagining things, etc. What we usually call direct experience is perhaps direct at the surface of the sense organs, but from there it is processed by the mental structures, perceptual and conceptual, that have been built largely on the basis of previous experience. What reaches our awareness is generally the result of several or many steps of selection and integration of what is received by the sense organs. It follows that the only thing we experience directly is our own mental activity (Lamb 1998).

Experientialist cognition (Lakoff 1987) takes experience as active functioning as part of a natural and social environment. It takes common human experience as motivating what is meaningful in thought. "Motivating" does not mean "determining" (Lakoff 1988). With regard to the cognitive systems, there are great similarities in the general outlines of the architecture combined with innumerable differences of detail between individual systems. As Lamb (1998) puts it, the resemblances are doubtless to be attributed largely to the common genetic inheritance of our human information processing apparatus, while the differences result mainly from different experiences of individual cognitive systems during their diverse lifetimes.

In monolingual cases, building up the mental lexicon takes place while acquiring L1, however, it is subject to changes all through the person's life. Recalling is a reconstruction of the very mental state in which the given information was fixed (Gósy 1998b). Different languages make different distinctions explicit and have different patterns of lexicalisation. Macroplanning is language-independent, microplanning is language-specific (Green 1993). In the case of bilinguals, the relationship between a given L2 word and a given L1 word in the mental lexicon will vary from individual to individual, depending on how the words have been acquired and how well they are known, and also on the degree to which formal and/or semantic similarity is perceived between the L2 word and the L1 word in question (Singleton 1999).

Now the question is how the mind accommodates two linguistic systems and how reality is reflected through linguistic devices. Do bilinguals store information centrally and do they have equal access to it with both languages, or is information storage linked to separate languages, i.e., in two separate mental lexicons (Appel-Muysken 1987)?

One important model for bilingual representation is that developed by Kroll and her colleagues (Kroll 1993). In their framework, the lexical representations for the two languages are represented independently of each other but they share a single conceptual representation. As language proficiency in- 
creases, the connection between the word and its meaning becomes more direct, relying less on a mediating connection through the L1 lexicon. The degree of meaning similarity between the words within a translation pair may ultimately determine the bilingual representational form. The more similar the meanings of the translations, the more likely they are to be stored compoundly in the mental lexicon. For many words in one language a truly equivalent term does not exist in the other language (de Groot 1993).

From a neurophysiological aspect, a tentative conclusion based on studies of polyglot aphasia is that different languages are generally represented in the same area of the brain. It had long been wrongly thought that bilinguals use the right hemisphere more than monolinguals do, especially bilinguals who acquired a second language after childhood. Paradis (1981) proposes that languages are stored in a single-extended system, but the elements of each language form separate subsystems within a larger system.

\subsection{Bilingualism and biculturalism}

Bilingualism, according to Grosjean (1996), is the regular use of two or more languages or dialects in everyday life. The bilingual is not the sum of two monolingual persons in one, and very rarely can we find people who are balanced and equally fluent in their two or more languages. As he states in his Complementary Principle: "Bilinguals usually acquire and use their languages for different purposes, in different domains of life, with different people. Different aspects of life normally require different languages".

It is essential to refer to biculturalism when discussing the bilingual language representation. However, bilingualism and biculturalism are not necessarily coextensive. What is more, the balanced bicultural is as rare as the balanced bilingual. At the same time, everybody belongs to a number of cultures (or cultural networks), as Grosjean (1996) claims: major cultures (national, linguistic, social, religious, etc.) and minor cultures (occupation, sport, hobby, etc.). The criteria for biculturalism are as follows: living in two cultures, adapting to them, and blending aspects of each. Most biculturals have stronger ties with one culture than with another (at least in certain domains of life) but this in no way makes them less bicultural. According to Appel and Muysken (1987), it is cultural experience that seems to be important in establishing bilingual meaning systems rather than the acquisition context. 


\subsection{Language modes and code-switching}

In their everyday lives, bilinguals find themselves in various language modes on a monolingual-bilingual mode continuum. A mode is a state of activation of the bilingual's languages and language processing mechanisms (Grosjean 1997). At one end of the continuum, bilinguals are in a totally monolingual language mode: they are interacting only with monolinguals. One of the bilingual's languages is active and the other is deactivated as much as possible. At the other end of the continuum, bilinguals are in a bilingual language mode: they are communicating with bilinguals who share their two (or more) languages and this is the state where language mixing (i.e., code-switching and borrowing) may take place. In this case, both languages are active but the one that is used as the main language of communication (the base or matrix language) is more active than the other. These are end points but bilinguals also find themselves in between, depending on such factors as interlocutor, situation, content of discourse and function of interaction.

Putting a bilingual in a monolingual language mode allows one to study interferences (and other types of deviations) more easily but these also occur in the bilingual language mode, along with code-switching and borrowings (Grosjean 1995). Switching is not simply a haphazard behaviour due to some form of 'semilingualism' but, instead, a well-governed process used as a communicative strategy to convey linguistic and social information (Grosjean 1992).

What is interesting is whether it is the language structure that determines code-switching or there are other factors influencing it? Wei (1994) puts the emphasis on the complex character of code-switching and, based on his research carried out in some Chinese speech communities in North-East England, he concludes that besides linguistic factors there are emotional, social, psychological factors that come into play as far as code-switching is concerned.

In what follows, I will examine bilingual and bicultural semantic representation and its linguistic realisation through the analysis of three tests conducted among bilingual and bicultural subjects. I will also examine the switching attitudes of bilinguals in their interviews and in other experimental situations.

\section{Subjects and methods}

40 bilingual and bicultural subjects participated in the study, 20 women and 20 men. They are very different in terms of their languages and cultures, and the way they acquired their language other than Hungarian is also diverse. They 
all consider themselves bilinguals and biculturals in the sense of Grosjean's definition. The common factor about them is that they all live in Hungary and their language proficiency in both of their languages makes it possible for them to function as part of either language community, according to their needs. Table 1 contains the details about the subjects:

Table 1

Details of the subjects

\begin{tabular}{|l|c|c|c|c|}
\hline OTHER LANGUAGE & $\begin{array}{c}\text { NUMBER OF } \\
\text { SUBJECTS }\end{array}$ & $\begin{array}{c}\text { BORN IN } \\
\text { HUNGARY }\end{array}$ & $\begin{array}{c}\text { BORN IN } \\
\text { ANOTHER COUNTRY }\end{array}$ & AGE \\
\hline \hline Arabic & 2 & & 2 & 22,48 \\
\hline Chinese & 2 & & 2 & 14,18 \\
\hline Croatian & 2 & 1 & 1 & 23,30 \\
\hline Czech & 1 & 1 & & 25 \\
\hline English & 12 & 3 & 9 & $15-37$ \\
\hline French & 1 & & 1 & 14 \\
\hline German & 5 & 3 & 2 & $12-52$ \\
\hline Italian & 1 & & 1 & 32 \\
\hline Rumanian & 2 & & 2 & 21,25 \\
\hline Russian & 4 & 1 & 3 & $19-43$ \\
\hline Serbian & 3 & & 3 & $22-38$ \\
\hline Slovak & 3 & & 3 & $22-40$ \\
\hline Vietnamese & 2 & & 2 & 18,22 \\
\hline Total & $\mathbf{4 0}$ & $\mathbf{9}$ & $\mathbf{3 1}$ & \\
\hline
\end{tabular}

Table 2 shows the subjects' manner of becoming bilingual. For people belonging to the group of Bilingual First Language Acquisition (BFLA, Meisel 1989) the languages were used by both parents in accordance with the one parentone language strategy (Ronjat 1913) from the very birth of the child. Another group of bilinguals is the one where subjects belong to the Bilingual Second Language Acquisition (BSLA, Meisel 1989) category which means a certain age difference (but not more than one or two years) in the onset of the acquisition of the second language. I added the category of Late Second Language Acquisition that covers any age after two years at which the acquisition of the second language started and which resulted in bilingualism.

As mentioned above, people belonging to the BFLA group have always been exposed to two languages, irrespective of where they live. It was the parents' responsibility to provide them with both languages. People in the BSLA group (with the exception of one English subject who is the child of English monolingual parents who came to Hungary to work here with their one-year-old daughter) were born in linguistic minority situations either in 
Table 2

The categories of the subjects according to the ages of becoming bilinguals

\begin{tabular}{|l|c|c|c|}
\hline PEOPLE & $\begin{array}{c}\text { BILINGUAL FIRST } \\
\text { LANGUAE } \\
\text { ACQUISITION }\end{array}$ & $\begin{array}{c}\text { BILINGUAL SECOND } \\
\text { LANGUAG } \\
\text { ACQUISITION }\end{array}$ & $\begin{array}{c}\text { LATE SECOND } \\
\text { LANGUAGE } \\
\text { ACQUISITION }\end{array}$ \\
\hline \hline Arabic & & & 2 \\
\hline Chinese & & 1 & 2 \\
\hline Croatian & 1 & 1 & 1 \\
\hline Czech & 7 & & 4 \\
\hline English & & & 1 \\
\hline French & 4 & 2 & 1 \\
\hline German & & 3 & 3 \\
\hline Italian & & 3 & \\
\hline Rumanian & & & 17 \\
\hline Russian & 1 & $\mathbf{1 0}$ & \\
\hline Serbian & & & \\
\hline Slovak & & & \\
\hline Vietnamese & & & \\
\hline Total & $\mathbf{1 3}$ & & \\
\hline
\end{tabular}

Slovakia, Serbia, Romania or in one case in Hungary (a Hungarian Croat). They all were exposed to their first languages at home, and started second language acquisition - the acquisition of the language of the society -in nursery schools at about age two. The Arabic, French, Italian and Russian subjects were born in their homelands (i.e., in Lebanon, Jordan, France, Italy and Russia, respectively) and they arrived in Hungary in their late teens or early twenties to study at university, to work or after getting married to a Hungarian. In their case we speak about late second language acquisition which resulted in a fluent Hungarian language proficiency.

As far as the subjects' culture is concerned, they consider themselves biculturals since they have lived and functioned as parts of society in cultures other than Hungarian, too. Even those who have always lived in Hungary have very strong links with their other cultures either because of their national identity or because of the parents' maintaining their culture and identity and they opt for being a part of both cultures.

In what follows, I will concentrate on people who belong to two major cultures. The cultures of the subjects - apart from Hungarian - are as follows: Western-European (13), Central-European (9), Eastern-European (6), MiddleEast (2), Far-East (4), American (4), Australian (2). They were asked to carry out three experiments. 


\section{Experiment 1. Interview}

First the testees and the experimenters had an interview on the subjects' linguistic history and background putting in this way the bilingual into the bilingual mode. They were asked how they felt about being bilingual, how they acquired their languages, what they considered to be the advantages or disadvantages of being bilingual, about their cultures, their identity, etc. The conversations were audiotaped, transcribed and analysed from many different points of view. Here it is the bilingual language behaviour that is in the focus of attention with a special emphasis on their code-switching mechanisms in different language modes. The base language was Hungarian.

\section{Experiment 2. Colour naming test}

The subjects were asked to search their mental lexicon for the appropriate entry (colour word) and name 30 different shades of the following basic colours presented one after the other: green, blue, yellow, red, purple, brown, pink and grey. The goal was to find out how culture is reflected in their thoughts and, consequently, in their linguistic realizations. The shades were taken from the colour chart of the computer. The test was conducted in Hungarian as the base language but the participants were encouraged to use either or both of their languages. The results (1200 items) were counted and categorised according to the shades and the basic colours (for a different analysis, see Navracsics in press) and then analysed according to the sex-related differences in colour naming and from the point of view of language mixing.

\section{Experiment 3. Word association test}

The subjects were given the task to give the very first word that came to their mind after hearing 188 Hungarian stimulus words one after the other. The words were identical with those enumerated in 'Hungarian Verbal Associations' edited by Balló (1983) and Jagusztinné Ujvári (1985) and used in experiments carried out among Hungarian monolinguals back in 1979 and 1981 in the Debrecen region. The test was oral and audiotaped. The responses (7520 items) were categorised according to the links between the prime words and the activated words, and were analysed from many different points of view (cf. Navracsics 2000a,b; Navracsics 2001a,b).

When studying bilinguals, special attention must be paid to the language mode the bilinguals are in at the time of observation. Grosjean claims it is critical that researchers control for the mode subjects are in when they are being recorded or tested experimentally. The original question of ours whether bilinguals have one integrated semantic system or two independent systems is confounded with the language mode issue. "Failure to control for the bilingual 
mode factor produces at best variable data due to the fact that subjects are probably situated at various points along the monolingual-bilingual continuum, and at worst ambiguous data given the confound between this factor and the variable under study" (Grosjean 1997, 10).

During the experiments the subjects were asked to use their languages without any constraints, so the possibility of a bilingual language mode was offered to them. In most cases it was promoted by the experimenters being bilingual themselves. There were just a few exceptions, i.e., the interviews with the Arabic, Chinese and Vietnamese subjects where the subjects and the experimenters did not share the same languages so the subjects were in a monolingual language mode. In this study, our main concern was the activation of the two languages in different language modes during the experiment. We studied the speech behaviour of the bilinguals, with a special emphasis on the differences in their language use while giving an interview and while carrying out the other two experiments, and analysed the reasons for the code-switches that occurred.

\section{Results and discussion}

\section{Experiment 1. Interview}

During the interviews the involvement of the two languages was under investigation, the speech behaviour of the subjects was analysed. The base language was Hungarian. From among the 40 subjects, 16 switched to the other language and 24 of them did not do so. Those who switched were all in the bilingual mode and most of them did the switch only when they were speaking about something unique to their culture other than Hungarian (customs, traditions, or schooling). All the subjects, even those whose speech behaviour was characterized by a Hungarian-only language use, confessed that they used both languages in different domains of life with different people and in different situations.

Being in a bilingual mode makes the participants of the conversation feel free to "go in and out of their languages" (Grosjean-Miller 1994) and thus a lot of code-switches were expected. However, the subjects did not switch frequently to their other language but when they did so, they had a good reason for that.

(i) Person-related language use

Ati (an English-Hungarian bilingual, 30), e.g., while giving the interview in Hungarian, was constantly talking aside to his daughter in English. However, 
the base language of the interview was so determining for him that, in spite of the experimenter's encouraging him to say anything in English that does not come to his mind in Hungarian, he said: I studied Russian. És utána meg idejöttem 'and then I came here', and so he switched back to Hungarian. The code switch was a very short one just to make the experimenter sure that he is convenient with his language use.

Suzanne (a German-Hungarian bilingual, 30), when speaking about how she talks to her children, said the following: én inkább azt mondanám, hogy der Weihnachtsmann kommt, tehát hogy a Télapó jön 'I would rather say that der Weihnachtsmann kommt, that is that Santa Claus is coming'. She quoted what she had said word by word and even switched the language but then she repeated the same in Hungarian even though she was aware that the experimenter spoke German, too.

(ii) Context-bound language use

Doris (an American-Hungarian, 20), e.g., when speaking about her school experiences back in the US, answered the Hungarian question: És mit választottál? 'And what did you choose?' in English: Spanish and piano. But then she went on basically in Hungarian and switched to English for just some words, which had Hungarian endings, e.g., awardjaim 'my awards'.

Zsuzsi (a Canadian-Hungarian, 19) did the same, e.g., accenttal "with accent'. When she was trying to find the right word in Hungarian and the experimenter wanted to help her and asked in English: Attitude?, she answered: Nem is attitude, hanem maybe his habits. 'Not attitude but maybe his habits' where it is only some of the function words that are in Hungarian, the content words are in English.

Antonio (an Italian-Hungarian, 32) had an unexpected telephone call from Italy just before the interview. When the interview started, for a couple of seconds he spoke in Italian to the experimenter but then he switched to Hungarian, and there were no more code-switches during the interview.

Bernhardt (a German-Hungarian, 14) was also offered to use either of his languages. He wanted to do and did the interview in German, whereas during the other two experiments he used mainly Hungarian with some switches to German.

In the monolingual mode there were no switches at all, which shows that the subjects had a very strong control over their language use in the interviews.

\section{Experiment 2. Colour naming test}

In the data obtained, there were 1104 colour names altogether ( $8 \%$ of the answers were missing). Both the male and the female subjects were supposed to name a total of 600 colour shades. However, males did not name the colour 
in $11 \%$ and female subjects in $5 \%$ of the cases. The answers were put into the following categories with respect to the linguistic devices the subjects had chosen to express the most accurate shade:

(i) basic colour name (green, blue, etc.) consisting of one lexeme;

(ii) basic colour name plus quantifying adjectives: light, medium and dark;

(iii) basic colour name plus qualifying adjectives (military green, brownish pink, etc.)

(iv) basic colour name plus nominal qualifier (sky blue, midnight blue, field green, peanut brown, etc.)

Figure 1 shows the percentages of the different categories:

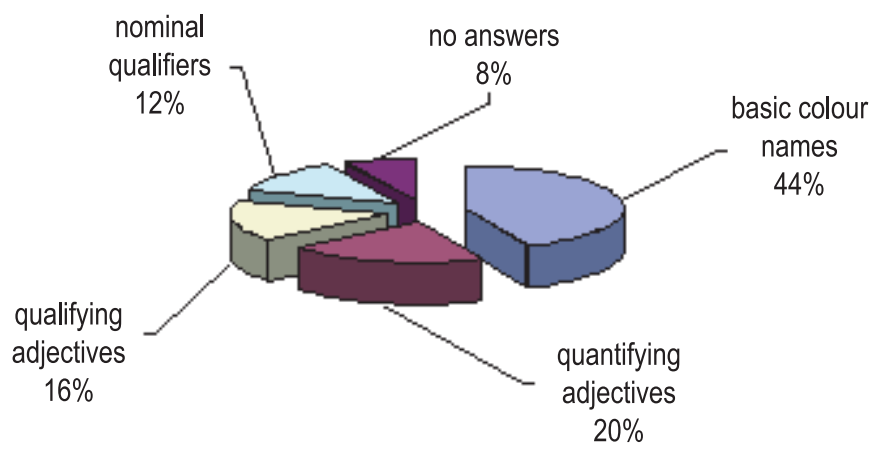

Fig. 1

Results of the colour naming test

The colour spectrum is a continuum which is generally parcelled out into six segments: purple, blue, green, yellow, orange, red (Steinberg 1992). In the data obtained, pink, brown and grey were added to the basic colour names. However, it was not essential to distinguish between the two colours yellow and orange from a linguistic point of view since the colour 'orange' is denoted by a compound word in Hungarian made up of 'orange' and 'yellow'. The Hungarian language treats this colour as a subcategory of the colour 'yellow'. As can be seen in this example, finer shades require a more elaborate vocabulary.

However, it is not always the same with different cultures. The Dani language of New Guinea, e.g., has only two colour words, one for light colours and one for dark colours (Steinberg 1992). Referring to what has been said in the Introduction, if language were the basis of thought and of the perception of nature, speakers of the Dani language would be expected to have perceptual 
difficulty in distinguishing colours they have no terms for, once they have a limited repertoire of colour terms. Research, however, has shown that this is not the case. Speakers of languages that have only two, three or four colour terms are as capable of perceiving differences in the visible spectrum as those whose languages have more than eight basic colour terms. People can see the differences but will not give them a name unless there is a good reason to do so. With regard to colour words, speakers who must remember a colour but do not have a word form for it have more trouble remembering it than speakers who do have such a form. Kay and McDaniel (1978), in a cross-cultural investigation, found no evidence in perception of colours for different language speakers. They conclude that '[...] rather than language determining perception, it is perception that determines language.' (Kay-McDaniel 1978, 610, quoted in Steinberg 1992).

How the habits of naming can affect our thinking can also be shown through recognition tests. The monolingual speaker of the Zuni language, e.g., presented with a small set of different colours and then asked after a period of time to pick out the ones he saw from a larger collection, will have trouble recognising the colours for which his/her language does not have convenient names. Where the experience is discrete, languages are apt to have more easily translatable terms. "It would be strange if $d o g$ or tooth did not have a same corresponding term in every language of the world, exactly equivalent at least in the central area of its meaning" (Bolinger 1968). But in continuums, like the visual spectrum, all the other things we experience are carved up in different ways.

The fact that the most frequently used category was the basic colour name itself (44\%) proves that the subjects did not really have problems or hesitations in recognising the presented colours. What is more, there were no problems with the correct recognition of the colours, either. However, Figure 1 also shows that the speakers' structuring of the spectrum was not careful enough since they did not really make serious attempts at distinguishing the different shades. The second most frequently used method of naming was adding the quantifying adjectives 'light', 'medium' or 'dark' to the basic colour name (20\%). Colour names with qualifying adjectives and nouns are the indicators of the subjects' attempts at being careful about naming the correct shades. These are altogether $28 \%$, scarcely more than the second category. These expressions tell the most about the culture of the subjects. Their metaphors, similes talk about their views and their perception of the world. Their biculturalism is expressed in their use of colour names unusual in the Hungarian culture, e.g., guerrilla green, midnight blue, sky blue, Adriatic blue, Adriatic green, 
lettuce green, lettuce blue, leaf green, moss green, sea-weed green, lichen green, sunset yellow.

Figure 2 shows the same categories in terms of sex-related colour naming (data given in percentages).

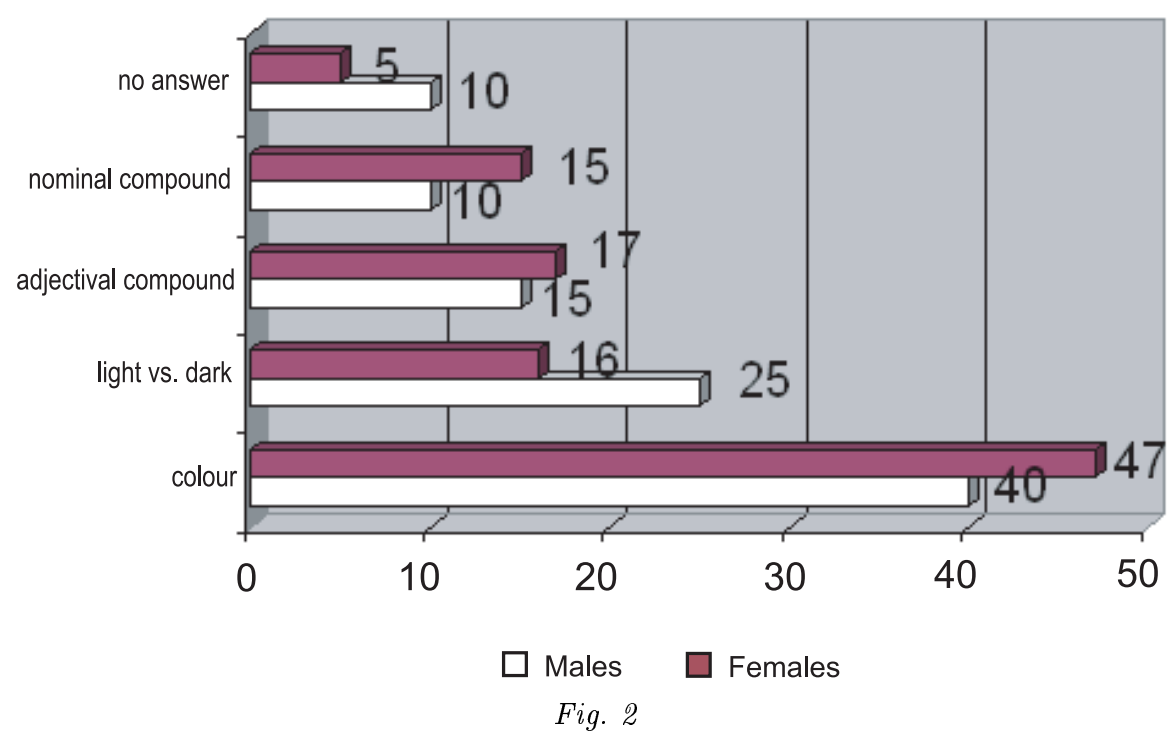

Sex-related differences in colour naming

Females gave the basic colour name more frequently (47\% as opposed to $40 \%$ ), but they were also more active in responding with compounds consisting either of an adjective or a noun plus the basic colour name. Males, at the same time, preferred using the adjectives 'light' or 'dark' (the adjective 'medium' was used in only one case to express a shade of blue, see also in Navracsics in press). In the 'no answer' category it is again the males who outnumbered females in failing to express the shade or name the colour. It has been argued by Rich (1977) that sex-related differences in the colour lexicon may be the result of cultural factors including greater concern for clothing on the part of women.

Among basic colours, it was red, pink and turquoise which were the most frequently used ones, which means these are the colours which have no shades or at least their shades are the least observable. The analysis of the 'light' versus 'dark' qualifiers made it clear that green is the most popular in this category and the least popular ones were orange, red, pink and gold. Besides, it is usually the 'light' shade which is specified as opposed to the 'dark' one. Qualifying adjectives were used mainly with the colour blue whereas they were 
never used with brown or red colours. No nominal compounds were used for red or pink; however, lots of them were applied with the colours yellow, green and blue.

When judging the correctness of colour naming, we must state that the subjects were able to identify correctly the same colours. It was curious to see which colours were named identically by all the subjects. They were brown, red and pink. However, it was also discovered that the colours dark yellow and greenish yellow were named by all the participants as green or different shades of green. Dark red was identified as brown in the case of German-Hungarian subjects in 57\%, in English-Hungarian subjects $92 \%$ and by all the rest of the participants in $100 \%$, no matter what culture they belonged to. Plum blue was identified mostly as brown and purple, and just in a small number of cases as blue. Blue was sometimes named as lilac and vice versa.

There were no preferences in terms of colours concerning the language choice in the colour naming test. No particular colours induced code-switches in a very significant amount. I have examined the cases of code-switching in the eight basic colour names. Code-switching took place in the following percentages: brown: $30 \%$, grey: $28 \%$, lilac: $27 \%$, blue and green: $24-24 \%$, yellow: $23 \%$, pink and red: $21-21 \%$.

Not all the participants switched to the other language in the test. This means that there were subjects who consistently used only one of their languages. A complete lack of switches was found in the colour naming of 22 subjects. From among them, two English-Hungarian and one German-Hungarian subjects used only English and German, respectively, and the rest (18 subjects) used only Hungarian.

As for sex-related differences, $62 \%$ of male and $32 \%$ of female subjects switched to the other language while naming colours. From among the male subjects, code-switches occurred in 96\% in the test of Pál (English), 93\% in Ku (Vietnamese), 80-80\% in Mihály (English) and Antonio (Italian). The English subjects were in a bilingual mode so there is nothing strange about their language choice, they knew that the experimenter understood what they were saying. However, the other two (i.e., the Vietnamese and the Italian) were in a monolingual mode, and still switched to their first language. They belong to the late second language acquisition category. No matter how fluent they are in Hungarian in their spontaneous speech, in a test situation, when trying to lexicalise their semantic representations, they turned to their dominant language in $80 \%$ of the cases.

Approximately to the same extent were both languages used in the tests of Szilvia (Slovak: 63\%), Galina (Russian: 40\%), Doris (English: 47\%) and 
Ati (English: 30\%). They all were in a bilingual language mode with the exception of Szilvia. She was the one who seemed to ignore the fact that the experimenter did not speak her language, and again, just like in the case of the others who did not switch at all, her aim was to reflect reality the way she saw it, and the linguistic device for the execution was not considered.

What were the reasons for code-switching in the test?

(i) The exact colour name is only in the lexicon of the vernacular language of the subject, e.g., sutmurasta: Serbian, trolevisna: Croatian.

(ii) For a more exact expression of the colour name, e.g., midnight blue, very rich colour of pink: English, lichen green: Vietnamese.

(iii) Not knowing the right colour name in Hungarian, e.g., turquoise: English, occramattone, celeste: Italian, gris: French.

(iv) One word missing in the lexicon of one language may trigger a total switch to the other language, like in the case of Ati (English) who named the first 21 colours in Hungarian and then - not knowing the right name- he switched to English and, as a result, he named all the rest of the colours in English.

(v) Retrieval is quicker in the other language, supposedly due to frequency and the age at which the word was acquired. Galina and Nadeshda (both are Russians), e.g., named the basic colours in Russian; however, they named all the shades, the elaborate colours in Hungarian. This might be due to the fact that they spent their childhood in Russia being monolinguals. As Gósy (1998a) puts it, too, children usually use the basic colour names. Elaborate colour names appear only later. In their lexicons the basic colour names were more quickly accessible in Russian and the elaborate colour names in Hungarian.

In some cases actual code-switch did not occur, however, the cultural differences were reflected in mirror translations, e.g., sea-weed green (Vietnamese), leaf green (English), field green (Russian), guerrilla green (Serbian), lettuce blue (Russian), salmon pink (Slovak), gold green (German), sky blue (Croatian), sunset yellow (Croatian) which were named in Hungarian.

\section{Experiment 3. Word association test}

The total number of responses were 7520 items which were categorised according to the links between the prime word and the activated words. The following links were discovered during the test: semantic, syntactic, lexical equivalents, morphological, phonetic. Besides these categories, two additional ones were made up, the 'zero' category, where there was no answer, and the 
'random' category, where no special links could be traced between the stimulus and the response.

Thus, the semantic category is made up of responses, independently of language, which belong to the same semantic field, synonyms, antonyms, idioms. Syntactic links can be discovered if the subjects used phrases which contain the stimulus word. The lexical category assumes direct associations between the lexical representations of the equivalent words in the bilingual's two languages. The morphological category involves words which are the results of word formation, compounding, affixation, etc. This category could be a subcategory of the semantic one. In the phonetic category, for various reasons, it is the sounds of words that elicit the retrieval. The reasons may be identical sounding $($ hold $($ English $)=$ tart $($ Hungarian $)-$ hold $($ Hungarian $)=$ moon (English)) or very similar sounding due to neighbourhood effects, cognate and homophonous noncognate status.

Let us focus our attention on the switches between the languages. $14 \%$ of the responses were given in the other language by the subjects. The total number of code-switches contained the same categories as mentioned above. However, only $1 \%$ of the responses could be categorized as a switch based on a phonetic stimulus or whose links to the stimulus word could not be recognized. $21 \%$ of the code-switches give evidence of semantic links between the stimulus word and the response. In these cases, the semantic representation was expressed independently of the form, i.e., the subjects did not care about the actual language choice. They were rather conscious about conveying the information and trying to reflect what they had in mind in connection with the given stimulus word, e.g., négyzet 'square' - corner, ablak 'window' - door, lassú 'slow' - fast, oldal 'page' - book, erdô 'forest' - zurka 'trip' (Serbian), fiú 'boy' - dievca 'girl' (Slovak), hosszú 'long' - krátki 'short' (Slovak), reggel 'morning' - večer 'evening' (Slovak), éhes 'hungry' - Wendy's cheeseburger, hely 'place' - Zagreb, kérdezni 'to ask' - repondre 'to answer' (French), ágy 'bed' - schlafen 'to sleep' (German), tolvaj 'thief' - prison. This means that subjects applying this manner of retrieval have a common semantic representational system whose operation does not depend on the actual language being used. This is what Weinreich (1968) called compound bilinguals and what has been criticized so severely lately. According to Weinreich's theory, the compound bilingual has one conceptual system and different linguistic realizations.

The other category, as Weinreich puts it, is the coordinate bilingual who acquired his/her languages in different contexts and, consequently, the languages are labelled. This kind of bilinguals have lexical items for each concept belonging to each of their languages, and it is not so much the concept but 
rather the lexical item that is important for them. I consider subjects who used a lot of mirror translations in the word association test belong to this category since they gave responses like e.g., szabad 'free' - free, ablak 'window' - window, Fenster (German), érteni 'to understand' - rozumet (Slovak), hely 'place' - mesto (Russian), etc. An amazingly large number of lexical links could be observed in the test: $60 \%$ of the responses were actually mirror translations, which tells a lot about the subjects' language acquisition patterns. The subjects belonging to the coordinate category had acquired their languages in separated language contexts, either in the one parent-one language fashion or in situational contexts.

The syntactic links that were discovered in the data also tell about the language acquisition of the subjects. Quite a few of them used the stimulus words in a context, i.e., they put them in phrases and made sometimes whole sentences with them (18\%).

Other triggers of code-switching were, e.g., phonetic similarities: drága 'dear' - dragon, ad 'give' - add, öröm 'joy' - a room, tér 'square' - tear, vaj 'butter' - wire, beszél 'speak' - sailboat, etc., but retrieval like this was less than $1 \%$.

In what follows, I will compare the percentages of switches in both tests (WAT $=$ word association test). Only those subjects are enumerated who exhibited code-switching (24 people altogether out of the 40).

14 subjects were in the bilingual and 10 in the monolingual language mode. Based on the presumption that people in the bilingual language mode switch between codes freely, here a large proportion of code-switches was expected in the bilingual, and a small number of switches in the monolingual mode. However, no significant differences were found in the amount of code-switches, as can be seen in Table 3 (overleaf). Or, at least, the differences in the majority of cases were apparently not due to the language mode.

Doris, Szilvia, Galina, Nadeshda, Ati, Mihály and Tamás were the ones whose switches were more or less balanced; they all - with the exception of Szilvia - were in the bilingual language mode. Christa and Zsuzsi did not switch at all, but they differed from the others in not switching from the guest language (i.e., the supposedly less activated language, Grosjean 1997) to Hungarian even though the base language of the experiments was Hungarian. They were also in the bilingual mode. Christopher used 100\% English colour names but only $69 \%$ English responses in the word association test.

Marie-France and Antonio had significant differences in their language behaviour in the two tests: neither of them used their first language in the word association test but both of them did switch in the colour naming one. 
Table 3

Code-switching expressed in \% in Experiments 1 and 2

\begin{tabular}{|c|c|c|c|c|c|}
\hline NAME & LANGUAGE & $\begin{array}{l}\text { LANGUAGE } \\
\text { MODE }\end{array}$ & $\overline{A G E}$ & $\begin{array}{c}\text { PERCENTAGE } \\
\text { OF SWITCHES } \\
\text { IN WAT }\end{array}$ & $\begin{array}{c}\text { PERCENTAGE } \\
\text { OF SWITCHES IN } \\
\text { COLOUR NAMING }\end{array}$ \\
\hline Christopher & English & "bilingual & $\overline{14}$ & 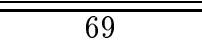 & 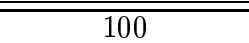 \\
\hline Ádám & Czech & monolingual & 15 & 12 & 0 \\
\hline Tamás & English & bilingual & 15 & 32 & 10 \\
\hline Marie-France & English & bilingual & 15 & 0 & 53 \\
\hline Há & Vietnamese & monolingual & 18 & 36 & 3 \\
\hline Zsuzsi & English & bilingual & 19 & 96 & 100 \\
\hline Doris & English & bilingual & 20 & 40 & 47 \\
\hline Pál & English & bilingual & 20 & 0.5 & 96 \\
\hline Tim & English & bilingual & 21 & 4 & 13 \\
\hline$\overline{\mathrm{Ku}}$ & Vietnamese & monolingual & 22 & 34 & 93 \\
\hline Szilvia & Slovak & monolingual & 22 & 73 & 63 \\
\hline Zorán & Croatian & monolingual & 23 & 29 & 0 \\
\hline Laurent & French & bilingual & 25 & 20 & 3 \\
\hline Lóri & Serbian & monolingual & 28 & 3 & 3 \\
\hline Ati & English & bilingual & 30 & 15 & 30 \\
\hline Irina & Russian & bilingual & 30 & 6 & 0 \\
\hline Janic & Croatian & monolingual & 30 & 2 & 3 \\
\hline Antonio & Italian & monolingual & 32 & 0 & 80 \\
\hline Kriszta & Serbian & monolingual & 38 & 7 & 0 \\
\hline Mihály & English & bilingual & 38 & 62 & 80 \\
\hline Ildikó & Slovak & monolingual & 40 & 5 & 0 \\
\hline Nadeshda & Russian & bilingual & 43 & 5 & 20 \\
\hline Galina & Russian & bilingual & 45 & 33 & 40 \\
\hline Christa & German & bilingual & 45 & 98 & 100 \\
\hline
\end{tabular}

The reason might be the simple fact that the stimulus words were given in Hungarian, which had a control over the language used throughout the testing time in the WAT, whereas they had no stimulus words in Hungarian apart from the introduction of the task when they were instructed to name the presented colours.

On the other hand, there were 16 subjects who did not switch at all in either of the tests though 9 of them were in the bilingual language mode. 


\section{Conclusions}

Language mode determined the subjects' language behaviour in such a way that they did not switch in the monolingual mode except in some cases (and some subjects only) when they were talking about linguistic entities not existing in Hungarian. The majority of code-switches occurred in the bilingual mode even though there were subjects in this mode who did not switch at all. The base language determined the language of the interviews, and the subjects seemed to have a stronger control over their languages during the interviews than during the other two tests. They might have felt more strongly that they were being investigated. The less natural circumstances made a strong influence upon their language behaviour. On the other hand, in the colour naming and word association tests, they wanted to meet the expectations and did not make so much effort to control their language use.

In the colour naming test only half of the subjects switched codes. Out of the 20 subjects who switched to the other language, 10 were in a bilingual and 10 in a monolingual language mode. The ones in the bilingual mode could have been expected to switch between their languages but they did not do so. For them the base language of the experiment, which was Hungarian, must have been a determining factor in the choice of language. On the other hand, the subjects who used the other language did so in spite of being asked in Hungarian. They might have wanted to prove that they knew their other language, too.

With respect to the sex-related differences in the colour lexicon of bilinguals, it can be assumed that the differences are not significant and are based on experiential and cultural factors rather than on biological ones. A linguistic code for a colour, the colour word is linked with a physical code for the colour, the perceptual representation. According to Rosch $(1975 \mathrm{a}, \mathrm{b})$, when a particular colour is presented to an individual, he or she generates or accesses the mental representation of the colour from his or her colour space. The findings that women are better at naming elaborate colour terms suggest the possibility that a woman's colour lexicon contains not only more linguistic labels than that of a man, but also a larger number of internal representations or physical codes. Nowaczyk (1982) found bigger differences between the sexes in his study conducted among monolinguals. Here, the differences are not significant which might be due to the subjects being bilingual and bicultural. The importance of culture in the reflection of the outside world projected in our internal representation has been justified. 
The analysis of the word association test has shown that besides culture, the manner of language acquisition is also important in the internalisation of the world. Bilinguals store the information in a more complex way than monolinguals do. The outcome of the lexical access is largely dependant on the way the language was acquired. Most links turned out to be semantically based, which also underlines the importance of the common semantic representational form.

It must be concluded that language, speech, or behaviour, is not the basis of thought and that the language system per se does not provide the specifics of one's view of nature and culture. A semantic component can be universal because it is part of people's normal cognitive make-up, such as the human ability to perceive shapes and colours. We dissect the universe along lines laid down by nature and by our communicative and cognitive needs, rather then by our language. The meanings of linguistic items can be adjusted to our needs by metaphorical extensions (Hudson 1986).

Bilingualism is different from monolingualism in multiple ways not just because bilinguals know two languages but because the mental organization that underlies language and thought is different (Bialystok 1998). It is clear that experimental situations activate both languages in the bilingual. But to what extent these languages are activated depends on various factors. It was only recently that de Groot (1995), on the basis of an extensive review of the literature, came to the conclusion that the bilingual memory does not exist. However, as it was seen in the tests, fluent bilinguals can sometimes use conceptual representations that are shared across their two languages. The memory of every individual is likely to contain structures of various types and these structures will occur in different proportions across bilinguals. This will depend on factors such as level of proficiency of the languages known, the characteristics of the words, the strategy used to learn them, the context in which the languages are used, the age at which a language was acquired.

Data analysed in this paper seem to support the claim that the language context may play an overwhelming role in the choice and use of language in experimental situations. The more anxiety the subjects have to overcome, the more they tend to use both of their languages for the sake of a better accomplishment. The less anxiety is present, the more conscious and careful language use can be observed. In an interview situation, they concentrate not only on the notions but also on the form, whereas in an experiment they are more concerned about delivering the message, expressing the semantic representation rather than caring about their actual language use or bothering about the ways of linguistic realisation of that semantic representation. 


\section{References}

Appel, René-Pieter Muysken 1987. Language contact and bilingualism. Edward Arnold, London.

Baker, Colin - Sylvia Prys Jones 1998. Encyclopedia of bilingualism and bilingual education. Multilingual Matters, Clevedon.

Balló, Larissza 1983. Magyar verbális asszociációk I [Verbal associations in Hungarian I]. JGYTF, Szeged.

Bialystok, Ellen 1998. Beyond binary options: effects of two languages on the bilingual mind. In: Studia Anglica Posnaniensia $33: 47-60$.

Bolinger, Dwight 1968. Aspects of language. Harcourt, Brace \& World, New York.

Gósy, Mária 1998a. Színmegnevezések gyermekkorban és felnôttkorban [The use of colour terminology by children and adults]. In: Zsolt Lengyel-Judit Navracsics (eds) Alkalmazott nyelvészeti tanulmányok II [Studies in applied linguistics II], 55-69. Veszprémi Egyetem, Veszprém.

Gósy, Mária 1998b. Szókeresés a mentális lexikonban [Retrieval of words in the mental lexicon]. In: Magyar Nyelvôr 122:189-201.

Green, David 1993. Towards a model of L2 comprehension and production. In: SchreuderWeltens (1993, 249-79).

Groot, Anette de 1993. Word-type effects in bilingual processing tasks. In: SchreuderWeltens (1993, 27-53).

Groot, Anette de 1995. Determinants of bilingual lexicosemantic organisation. In: Computer Assisted Language Learning $8: 151-80$.

Grosjean, François 1992. The bilingual and the bicultural person in the hearing and in the deaf world. In: Sign Language Studies $77: 307-20$.

Grosjean, François 1995. A psycholinguistic approach to code-switching. In: Lesley MilroyPieter Muysken (eds) One speaker, two languages. Cross-disciplinary perspectives on code-switching, 259-76. Cambridge University Press, Cambridge.

Grosjean, François 1996. Living with two languages and two cultures. In: J. Parasnis (ed.) Cultural and language diversity and the deaf experience, 20-37. Cambridge University Press, Cambridge.

Grosjean, François 1997. Studying bilinguals: methodological and conceptual issues. Manuscript.

Grosjean, François - Joanne Miller 1994. Going in and out of languages: an example of bilingual flexibility. In: Psychological Science 5 : 201-6.

Hudson, Richard 1986. Sociolinguistics. Cambridge University Press, Cambridge.

Jagusztinné Ujvári, Klára 1985. Magyar verbális asszociációk II [Verbal associations in Hungarian II]. JGYTF, Szeged.

Kay, Paul-Chad K. McDaniel 1978. The linguistic significance of the meanings of basic color terms. In: Language 54:610-46.

Kroll, Judith 1993. Accessing conceptual representation for words in a second language. In: Schreuder-Weltens (1993, 53-83).

Lakoff, George 1987. Women, fire and dangerous things: what categories reveal about the mind. University of Chicago Press, Chicago. 
Lakoff, George 1988. Cognitive semantics. In: Umberto Eco- Marco Santambrogio-Patrizia Violi (eds) Meaning and mental representations, 119-55. Indiana University Press, Bloomington.

Lamb, Sydney 1998. Pathways of the brain. John Benjamins, Amsterdam.

Meisel, Jürgen 1989. Code-switching in young bilingual children: the acquisition of grammatical constraints. In: Studies in Second Language Acquisition 16:413-39.

Navracsics, Judit 2000a. A mentális lexikon rendezettségének és a nyelvtanulás módjának összefüggései [The relation between the organisation of the mental lexicon and the methods of language learning]. In: István T. Molnár-Kinga Klaudy (eds) Papp Ferenc akadémikus 70. születésnapjára [For Ferenc Papp on his 70th birthday], 144-51. Kossuth Egyetemi Kiadó, Debrecen.

Navracsics, Judit 2000b. Word association test among bilinguals. In: Strani Jezici 29: $43-151$.

Navracsics, Judit 2001a. Kétnyelvüek mentális lexikonának jellegzetességei [The characteristics of bilinguals' mental lexicon]. In: Alkalmazott Nyelvtudomány 1:51-61.

Navracsics, Judit 2001b. Kétnyelvúek mentális lexikonának rendezettsége [The organisation of bilinguals' mental lexicon]. In: József Andor-Tibor Szűts-István Terts (eds) Színes eszmék nem alszanak. Szépe György 70. születésnapjára II. [Colourful ideas do not sleep. A Festschrift for György Szépe on his 70th birthday II], 865-74. Lingua Franca Csoport, Pécs.

Navracsics, Judit in press. A nyelvi relativitás többnyelvűek színmegnevezési tesztjében [Linguistic relativity in colour-naming tests of bilinguals]. In: Csaba Földes (ed.) MMI: Annuum tempus linguarum Europae. Scripta Philologica Pannoniensis. VEAB, Veszprémi Egyetem, Veszprém.

Nowaczyk, Ronald 1982. Sex-related differences in the color lexicon. In: Language and Speech $25: 257-65$.

Paradis, Michel 1981. Neurolinguistic organization of a bilingual's two languages. In: J. Copeland (ed.) The Seventh LACUS Forum 1980 (Columbia), 480-94. Hornbeam Press, Columbia.

Rich, Elaine 1977. Sex-related differences in color vocabulary. In: Language and Speech 20 : 404-9.

Ronjat, Jules 1913. Le developpement du langage observé chez un enfant bilingue. Champion, Paris.

Rosch, Eleanor 1975a. Cognitive representations of semantic categories. In: Journal of Experimental Psychology: General 104 : 192-233.

Rosch, Eleanor 1975b. The nature of mental codes for color categories. In: Journal of Experimental Psychology: Human Perception and Performance $1: 303-22$.

Schreuder, Robert-Bert Weltens (eds) 1993. The bilingual lexicon. John Benjamins, Amsterdam.

Singleton, David 1999. Exploring the second language mental lexicon. Cambridge University Press, Cambridge.

Steinberg, Danny 1992. Psycholinguistics. Language, mind and world. Longman, London.

Steinberg, Danny 1993. An introduction to psycholinguistics. Longman, London. 
Wei, Li 1994. Code-switching in the language of Chinese communities in North England. In: Durk Gorter (ed.) Code-switching and language contact, 264-84. Fryske Akademy, Leeuwarden.

Weinreich, Uriel 1968. Languages in contact. Mouton, The Hague.

\author{
Address of the author: Judit Navracsics \\ University of Veszprém \\ Department of Applied Linguistics \\ Egyetem u. 10 \\ H-8200 Veszprém \\ navracsj@almos.vein.hu
}

